\title{
ERG AND EOG ABNORMALITIES IN CARRIERS OF X-LINKED RETINITIS PIGMENTOSA
}

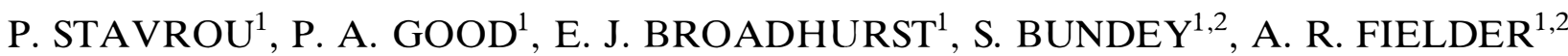 \\ and S. J. CREWS $\dagger$ \\ Birmingham
}

\begin{abstract}
SUMMARY
The diagnosis of $\mathrm{X}$-linked retinitis pigmentosa (XL$\mathrm{RP}$ ) relies on the identification of the female carriers, in whom fundal abnormalities are often minimal and variable. The electroretinogram (ERG) has been reported as abnormal in $\mathbf{5 4 - 9 6 \%}$ of heterogygote females. This study examines the combined use of electro-oculogram (EOG) and standardised ERG in 31 obligate and 33 non-obligate carriers of XL-RP. In the obligate carrier group, the EOG was abnormal in 13 carriers $(41 \%)$, the ERG abnormal in 21 carriers $(68 \%)$ and a combined EOG and ERG abnormality occurred in 24 carriers $(77 \%)$. An EOG abnormality alone occurred in 2 carriers $(6.5 \%)$. Fourteen obligate carriers $(45 \%)$ showed a peak to peak delay of the ERG scotopic b wave, this being a previously unreported phenomenon. Similarly, in the non-obligate carrier group, the EOG was abnormal in 11 carriers $(44 \%)$ and the ERG abnormal in 19 carriers $(73 \%)$. The results of this study suggest that the use of both tests, including measurement of the scotopic b wave latency, may increase the carrier detection rate.
\end{abstract}

Retinitis pigmentosa (RP) is a group of retinal disorders of unknown aetiology, characterised by progressive degeneration of rods and cones. While it may occur sporadically, there are at least three modes of inheritance: autosomal dominant, autosomal recessive and X-linked. ${ }^{1}$ In the $\mathrm{X}$-linked type of RP (XL-RP) the affected male hemizygotes suffer from severe retinal degeneration while the female heterozygotes show variable retinal dysfunction. ${ }^{2-7}$

The identification of carriers of XL-RP is important for genetic counselling. This can be relatively easy for females who belong to a known pedigree of XL-RP, and are therefore obligate carriers. How-

$\dagger$ Deceased.

From: ${ }^{1}$ Birmingham and Midland Eye Centre, Birmingham; ${ }^{2}$ University of Birmingham Medical School, Birmingham, UK.

Correspondence to: Mrs P. Stavrou, FRCS, Birmingham and Midland Eye Centre, City Hospital NHS Trust, Dudley Road, Birmingham B18 7QH, UK. ever, it can be difficult for females who have less well documented pedigrees, or in whom the pedigree lies on the maternal side, or who have a son with severe RP but no other family history. The diagnosis of the heterozygous state in these women is based, in clinical practice, on fundus appearance and electrodiagnostic tests. Other investigations, which are not widely available, include measurement of rhodopsin pigment density by fundus reflectometry, ${ }^{8}$ and vitreous fluorophotometry detecting defects in the blood-retinal barrier. ${ }^{7}$

The fundus changes in female carriers of XL-RP are variable. Some carriers have no ophthalmoscopically detectable abnormality, while others exhibit a tapetal reflex across the posterior pole, peripheral patches of atrophy of the retinal pigment epithelium, pigmentary clumping in the form of bone spicules, disc pallor and constricted retinal arterioles. ${ }^{1-4,6,7}$ Some of these fundal features, such as pigmentary changes, can be subtle, and are therefore difficult to differentiate from the normal appearance in heavily pigmented Asian or Afro-Caribbean individuals. This variability in the ophthalmoscopical picture occurs not only in carriers from different pedigrees but also in members of the same family. $3,4,9$

To date, the main electrodiagnostic test performed in these patients has been the electroretinogram (ERG), which has been reported as abnormal in $50-96 \%{ }^{4-6,10-12}$ of XL-RP carriers. The use of the electro-oculogram (EOG) has been limited and its findings in this group of patients are not well documented.

In this study, we have investigated the combined use of ERG and EOG in the diagnosis of the carrier state of XL-RP.

\section{Patients}

The genetic files of all patients attending the Genetic Clinic of the Birmingham and Midland Eye Hospital 
over the last 20 years were retrospectively reviewed. XL-RP was diagnosed by pedigree analysis, which showed an absence of male-to-male transmission, and by assessment of the fundal, ERG and EOG characteristics of the affected males and female family members. In all families, retinal function was severely altered in the males while the females were, as a group, less affected. None of the carriers had any other ophthalmological abnormality.

For the purposes of this study, the female patients who were investigated for the heterozygous state of XL-RP, were divided into three groups:

Group 1: Obligate carriers. These are the females who belong to a pedigree in which there are at least two affected male relatives, one of them being the subject's father or son. These heterozygotes can confidently be recognised from the pedigree alone, before any electrodiagnostic tests are carried out.

Group 2: Possible carriers. These are the daughters of women who are known obligate carriers. They have a $50 \%$ risk of being carriers. The heterozygous state, in this group, was identified by the presence of at least fundal abnormalities.

Group 3: These are the women whose fundal abnormalities, in association with or without electrophysiological abnormalities, were responsible for the diagnosis of XL-RP being made in their isolated male relative. Most of them were mothers; the rest were daughters.

The results of EOG and ERG abnormalities of the three groups were compared to those of three ageand sex-matched control groups. The mean EOG and ERG results were analysed by Student's $t$-test. Incidences (\%) were compared by chi-squared analysis.

\section{Methods}

Electro-oculogram (EOG). The EOG was recorded from $\mathrm{Ag} / \mathrm{AgCl}$ skin electrodes on the inner and outer canthi of each eye. After 5 minutes of light adaptation with a photopic illumination of $30 \mathrm{ft}-\mathrm{L}$ on a Ganzfeld screen, $30^{\circ}$ ocular movements between two red target lights were recorded, for a total of 12 minutes in the dark. This was followed by 10 minutes of light adaptation using a $30 \mathrm{ft}-\mathrm{L}$ Ganzfeld illumination. The ocular movements were recorded, every 2 minutes throughout the test, using a Medelec Sensor clinical averager with a band pass filter of 1$250 \mathrm{~Hz}$. The Arden index was calculated by dividing the average of the two largest values in the light by the average of the two smallest values after 10-12 minutes in the dark. The normal range for the EOG, in our department, is $170-280 \%$.

Electroretinogram (ERG). The ERG was recorded by using Ganzfeld stimulation and Burian-Allen contact lens electrodes referred to an outer canthal
$\mathrm{Ag} / \mathrm{AgCl}$ electrode. Recordings were made with the pupils dilated with guttae tropicamide $1 \%$. A Nicolet CA1000 or Nicolet Spirit clinical averager was used to record the data. Frequency band pass filtering was set at $1-1000 \mathrm{~Hz}$.

Scotopic stimuli, recorded in all 64 patients, after 20 minutes of dark adaptation, consisted of an intense flash of $18.9 \mathrm{ft}-\mathrm{L}-\mathrm{s} /$ flash. The normal range for the intense flash ERG amplitude, in our department, is $290-800 \mu \mathrm{V}$ and the normal range for the intense flash scotopic b wave latency is $37-43 \mathrm{~ms}$. In addition, 10 of the 64 patients recorded over the past 18 months underwent scotopic ERG using standard flash (2.35 ft-L-s), intense flash (18.9 ft-L-s), and stimuli of 1,2 and $3 \log$ units below the standard flash. Reductions in stimulus intensity were provided by 1, 2 and $3 \log$ unit Kodak Wratten neutral density filters. The stimulus intensities from $3.00 \mathrm{log}$ units below to $1.00 \log$ unit above standard flash were calibrated using a flash photometer.

Photopic ERG was obtained following 5 minutes of adaptation using a Ganzfeld illumination of 30ft-L. The photopic stimulus intensity was $18.9 \mathrm{ft}-\mathrm{L}-\mathrm{s} / \mathrm{flash}$. This was followed by $30 \mathrm{~Hz}$ cone stimulation, using a background Ganzfeld illumination of $20 \mathrm{ft}-\mathrm{L}$ and a stimulus intensity of $4.8 \mathrm{ft}$.-L-s/flash. For scotopic stimuli 5 averages were obtained, while for photopic and $30 \mathrm{~Hz}$ stimuli 20 averages were obtained. Measurements of the ERG $b$ wave amplitude and latency were made of responses obtained from all the stimulus parameters used. The normal range for the photopic $b$ wave ERG amplitude, in our department, is $48-150 \mu \mathrm{V}$, and for the $30 \mathrm{~Hz}$ cone $\mathrm{b}$ wave amplitude is $25-120 \mu \mathrm{V}$. The normal range for the 30 $\mathrm{Hz}$ cone $\mathrm{b}$ wave latency is $26-33 \mathrm{msec}$.

Values were considered abnormal if they fell outside our laboratory normal range. The values of all control subjects were within this normal range.

\section{RESULTS}

Group 1 consisted of 31 obligate carriers. The mean age at the time of examination was 30.9 years (range 5-84 years). The age distribution was: 10 carriers under 20 years, 11 carriers between 20 and 40 years, and 11 carriers over 40 years. Group 2 consisted of 23 possible carriers. The mean age was 21.5 years (range 6-40 years). Group 3 consisted of 10 females. The mean age was 35.6 years (range $20-56$ years). The mean age of the control group was 31.2 years (range 6-58 years).

\section{Group 1: Obligate Carriers}

Fundal abnormalities (tapetal reflex and/or bone spicule pigmentation) were detected in 24 of 31 (77\%) obligate carriers. Five obligate carriers (16\%) had normal fundi but abnormal EOG and/or ERG. The remaining 2 obligate carriers, aged 5 and 30 
Table I. Mean EOG and ERG values in obligate carriers of XL-RP

\begin{tabular}{|c|c|c|c|}
\hline Investigation & $\begin{array}{c}\text { Group } 1 \\
(n=62 \text { eyes, } \\
31 \mathrm{pts})\end{array}$ & $\begin{array}{c}\text { Control } \\
(n=60 \text { eyes, } \\
30 \text { pts })\end{array}$ & Significance \\
\hline $\mathrm{EOG} \pm \mathrm{SD}$ & $170.2 \pm 19.6$ & $206.6 \pm 35.7$ & $p<0.005$ \\
\hline Range & $105-236$ & $172-286$ & \\
\hline \multicolumn{4}{|l|}{ Scotopic ERG amplitude } \\
\hline $\begin{array}{l} \pm \text { SD } \\
\text { Range }\end{array}$ & $\begin{array}{c}261.4 \pm 80.7 \\
95-526\end{array}$ & $\begin{array}{c}389.8 \pm 51.7 \\
296-595\end{array}$ & $p<0.005$ \\
\hline \multicolumn{4}{|l|}{ Scotopic ERG latency } \\
\hline $\begin{array}{l} \pm \text { SD } \\
\text { Range }\end{array}$ & $\begin{array}{l}44.9 \pm 5.63 \\
37.9-50.7\end{array}$ & $\begin{array}{l}41.8 \pm 3.24 \\
38.0-43.0\end{array}$ & $p<0.005$ \\
\hline \multicolumn{4}{|l|}{ Photopic ERG amplitude } \\
\hline $\begin{array}{l} \pm \text { SD } \\
\text { Range }\end{array}$ & $\begin{array}{c}56.6 \pm 22.1 \\
17.2-116\end{array}$ & $\begin{array}{l}62.9 \pm 16.9 \\
48.6-123\end{array}$ & $p<0.05$ \\
\hline \multicolumn{4}{|l|}{$30 \mathrm{~Hz}$ ERG amplitude } \\
\hline$\pm \mathrm{SD}$ & $35.7 \pm 14.6$ & $41.8 \pm 10.6$ & $p<0.025$ \\
\hline Range & $14.3-71.3$ & $26.2-65.7$ & \\
\hline $30 \mathrm{~Hz}$ latency \pm SD & $31.7 \pm 2.66$ & $29.3 \pm 1.92$ & $p<0.005$ \\
\hline Range & $28.1-35.3$ & $28.0-33.0$ & \\
\hline
\end{tabular}

EOG values are expressed as a percentage, latency values in milliseconds and amplitude values in microvolts. pts, patients.

years respectively at the time of examination, did not show any electrophysiological or fundal abnormality. Six obligate carriers $(19 \%)$ had what were considered abnormal fundi but a normal EOG and ERG.

The EOG was abnormal in 13 of 31 obligate carriers $(41 \%)$, with a mean Arden index of $139.8 \%$. In the obligate carrier group as a whole, the mean Arden index was $170.2 \%$, which was significantly reduced $(p<0.005)$ compared with the $206.6 \%$ in the control group (Table I). For obligate carriers with no EOG abnormalities, the mean Arden index was not significantly different to the mean value of the control group. The incidence of EOG abnormality
Table II. ERG, EOG and fundus abnormalities in various age groups of obligate carriers

\begin{tabular}{|c|c|c|c|c|c|c|c|}
\hline \multirow[b]{2}{*}{ Investigation } & \multicolumn{2}{|c|}{$\begin{array}{c}\text { Under } \\
20 \text { years } \\
(n=10 \text { pts })\end{array}$} & \multicolumn{2}{|c|}{$\begin{array}{l}20-40 \text { years } \\
(n=11 \text { pts }) \\
\end{array}$} & \multicolumn{2}{|c|}{$\begin{array}{c}\text { Under } \\
40 \text { years } \\
(n=10 \text { pts }) \\
\end{array}$} & \multirow{2}{*}{ Significance } \\
\hline & No. & $\%$ & No. & $\%$ & No. & $\%$ & \\
\hline EOG & 3 & 30 & 4 & 36 & 6 & 60 & $p<0.05$ \\
\hline ERG & 6 & 60 & 6 & 55 & 9 & 90 & $p<0.01$ \\
\hline Fundus & 7 & 70 & 9 & 82 & 8 & 80 & \\
\hline
\end{tabular}

increased significantly $(p<0.05)$ in carriers over 40 years of age, compared with younger ones (Table II). In 2 of the 11 carriers in the 20-40 year age group a reduction in the EOG was the only electrophysiological or fundal abnormality found.

Reduction of the scotopic b wave ERG amplitude occurred in 19 of $31(61 \%)$ obligate carriers, with a mean group scotopic b wave amplitude of $210.7 \mu \mathrm{V}$. In the obligate carrier group as a whole, the mean scotopic b wave amplitude was $261.4 \mu \mathrm{V}$, which was significantly reduced $(p<0.005)$ compared with 389.8 $\mu \mathrm{V}$ in the controls (Table I, Fig. 1). For obligate carriers with no ERG abnormalities, the mean scotopic b wave amplitude was not significantly different from the mean value of the control group. Delay as well as reduction of the scotopic $b$ wave occurred in 14 obligate carriers (45\%). As noted in the EOG findings, the incidence of scotopic ERG abnormality increased significantly $(p<0.01)$ in obligate carriers over 40 years, compared with younger ones (Table II). Unilateral scotopic ERG reduction occurred in 4 of $31(13 \%)$ obligate carriers.

Photopic and $30 \mathrm{~Hz}$ cone ERG were reduced in 14 of $31(45 \%)$ obligate carriers, while $30 \mathrm{~Hz} \mathrm{~b}$ wave

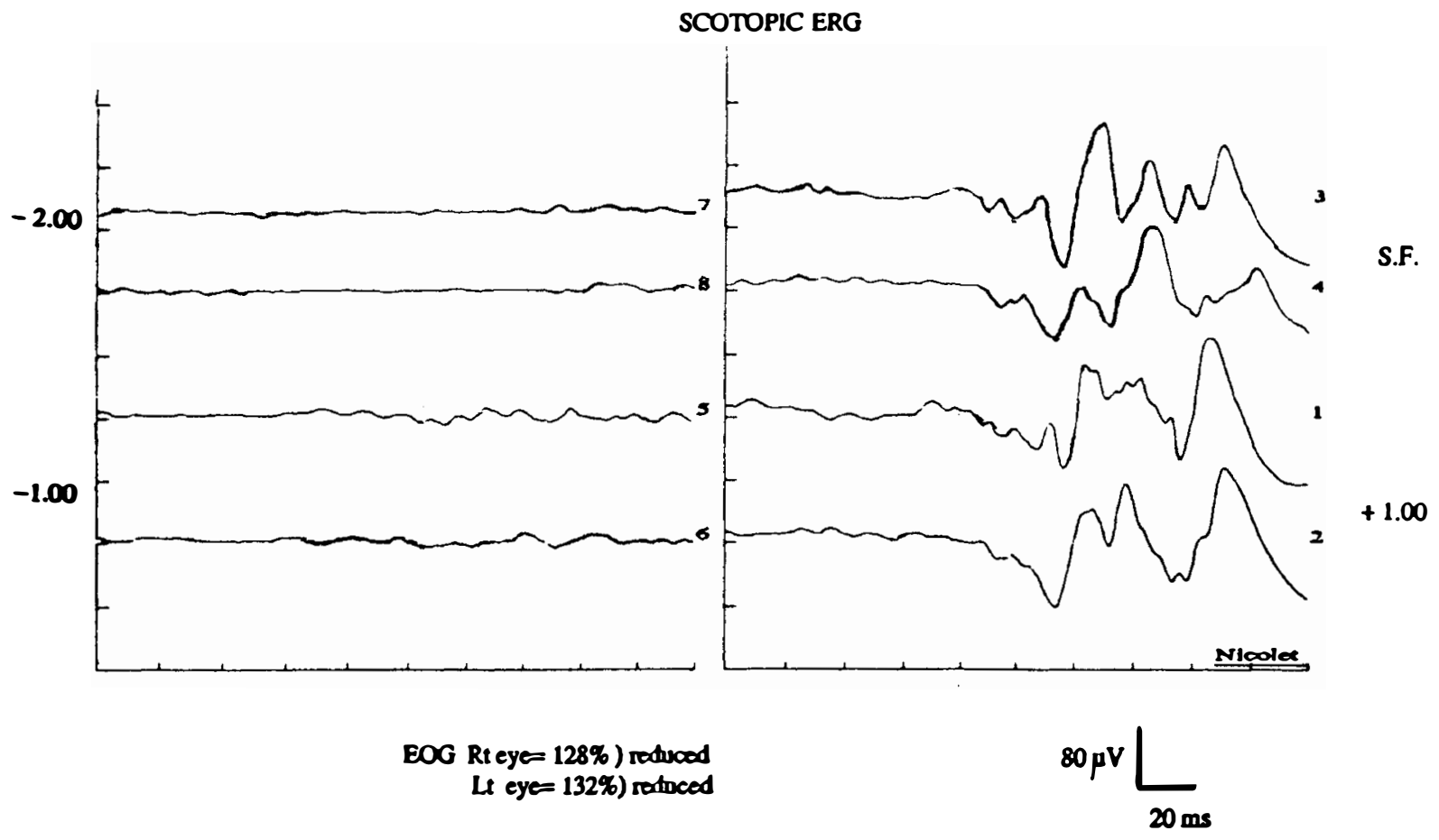

Fig. 1. BM, aged 43 years. Grossly reduced ERG to all scotopic stimuli. This subject also had marked reduction of EOG. 
Table III. Mean EOG and ERG values in female possible carriers of XL-RP with abnormal fundi

\begin{tabular}{|c|c|c|c|}
\hline Investigation & $\begin{array}{l}\text { Heterozygotes } \\
(n=32 \text { eyes, } \\
16 \mathrm{pts})\end{array}$ & $\begin{array}{c}\text { Control } \\
(n=44 \text { eyes, } \\
22 \mathrm{pts})\end{array}$ & Significance \\
\hline$\overline{\mathrm{EOG} \pm \mathrm{SD}}$ & $178.5 \pm 22.4$ & $210.5 \pm 27.7$ & $p<0.005$ \\
\hline $\begin{array}{l}\text { Scotopic ERG } \\
\text { amplitude } \pm \text { SD }\end{array}$ & $307.2 \pm 59.4$ & $397.9 \pm 38.7$ & $p<0.005$ \\
\hline $\begin{array}{l}\text { Scotopic ERG latency } \\
\pm \text { SD }\end{array}$ & $44.3 \pm 6.42$ & $41.2 \pm 3.30$ & $p<0.01$ \\
\hline $\begin{array}{l}\text { Photopic ERG } \\
\text { amplitude } \pm \text { SD }\end{array}$ & $58.6 \pm 20.7$ & $65.4 \pm 14.1$ & $p<0.05$ \\
\hline $\begin{array}{l} \pm \text { SD } \\
30 \mathrm{~Hz} \text { ERG latency }\end{array}$ & $37.9 \pm 14.6$ & $44.1 \pm 13.2$ & $p<0.025$ \\
\hline \pm SD & $32.0 \pm 3.92$ & $28.7 \pm 1.78$ & $p<0.025$ \\
\hline
\end{tabular}

EOG values are expressed as a percentage, latency values in milliseconds and amplitude values in microvolts.

latencies were delayed in 12 carriers (39\%). Delay of the $30 \mathrm{~Hz} \mathrm{~b}$ wave and reduction of the scotopic $\mathrm{b}$ wave amplitude were the only ERG abnormalities in 2 obligate carriers, both aged over 40 years.

\section{Group 2: Possible Carriers}

Fundal abnormalities were detected in 16 of 23 $(70 \%)$ possible carriers.

Six of the 23 females (26\%) had an abnormal EOG, with a mean Arden index of $138.3 \%$. Since 16 possible carriers $(70 \%)$ had an abnormal fundus and were therefore identified as carriers, the incidence of EOG abnormality converts to $38 \%$. In the group of these 16 carriers, the mean Arden index was $178.5 \%$, which was significantly reduced $(p<0.005)$ compared with controls (Table III). Two, of 7 possible carriers with normal fundi, had abnormal ERG but normal EOG and one further possible carrier had abnormal EOG but normal ERG.

Reduction of the scotopic b wave ERG amplitude occurred in 10 of $23(43 \%)$ possible carriers. Since $70 \%$ of possible carriers had an abnormal fundus, and were therefore identified as carriers, the incidence of scotopic ERG abnormality converts to $62 \%$. Delay, as well as reduction, of the scotopic b wave amplitude occurred in 8 of $23(35 \%)$ carriers. Reduction of the amplitude and delay of the photopic and $30 \mathrm{~Hz}$ ERG

Table IV. Mean EOG and ERG values in group 3 carriers of XL-RP

\begin{tabular}{|c|c|c|c|}
\hline Investigation & $\begin{array}{c}\text { Group } 3 \\
(n=20 \text { eyes, } \\
10 \text { pts })\end{array}$ & $\begin{array}{c}\text { Control } \\
(n=42 \text { eyes, } \\
21 \text { pts })\end{array}$ & Significance \\
\hline$\overline{\mathrm{EOG} \pm \mathrm{SD}}$ & $155.1 \pm 28.0$ & $198.5 \pm 24.4$ & $p<0.005$ \\
\hline $\begin{array}{l}\text { Scotopic ERG } \\
\text { amplitude } \pm \text { SD }\end{array}$ & $280.4 \pm 55.2$ & $372.4 \pm 36.5$ & $p<0.005$ \\
\hline $\begin{array}{l}\text { Scotopic ERG latency } \\
\quad \pm \text { SD }\end{array}$ & $44.7 \pm 3.91$ & $42.2 \pm 3.06$ & $p<0.05$ \\
\hline $\begin{array}{l}\text { Photopic ERG } \\
\text { amplitude } \pm \text { SD } \\
30 \mathrm{~Hz} \text { ERG amplitude }\end{array}$ & $56.7 \pm 16.3$ & $61.6 \pm 13.8$ & NS \\
\hline $\begin{array}{l} \pm \mathrm{SD} \\
30 \mathrm{~Hz} \text { latency } \pm \mathrm{SD}\end{array}$ & $\begin{array}{l}37.4 \pm 9.28 \\
31.8 \pm 2.41\end{array}$ & $\begin{array}{l}41.6 \pm 13.4 \\
29.0 \pm 1.17\end{array}$ & $\begin{array}{c}\text { NS } \\
p<0.01\end{array}$ \\
\hline
\end{tabular}

EOG values are expressed as a percentage, latency values in milliseconds and amplitude values in microvolts.
Table V. ERG, EOG and fundus abnormalities in various groups of XL-RP carriers

\begin{tabular}{|c|c|c|c|c|c|c|}
\hline \multirow[b]{2}{*}{ Investigation } & \multicolumn{2}{|c|}{$\begin{array}{c}\text { Group } 1 \\
(n=31 \mathrm{pts}) \\
\end{array}$} & \multicolumn{2}{|c|}{$\begin{array}{c}\text { Group } 2 \\
(n=23 \mathrm{pts})\end{array}$} & \multicolumn{2}{|c|}{$\begin{array}{c}\text { Group } 3 \\
(n=10 \mathrm{pts})\end{array}$} \\
\hline & No. & $\%$ & No. & $\%(\%)$ & No. & $\%$ \\
\hline EOG & 13 & 41 & 6 & $26(38)$ & 5 & $56^{\mathrm{a}}$ \\
\hline ERG & 21 & 68 & 12 & $52(61)$ & 7 & 70 \\
\hline Fundus & 24 & 77 & 16 & $70(100)$ & 10 & 100 \\
\hline
\end{tabular}

Group 1, obligate carriers; group 2, possible carriers. Percentages in parentheses in group 2 are converted incidences based on the $70 \%$ incidence of fundal abnormality in this group.

${ }^{\mathrm{a}}$ Nine of the 10 patients were tested (see text).

occurred in 7 of the $23(30 \%)$ possible carriers. One possible carrier had a normal amplitude of photopic and $30 \mathrm{~Hz}$ ERG but delay of the $30 \mathrm{~Hz}$ ERG. Mean ERG values are seen in Table III.

\section{Group 3}

All patients had fundal abnormalities.

Six of the 10 females $(60 \%)$ assessed had abnormal EOG, with a mean Arden index of $133.8 \%$. In group 3 as a whole, the mean Arden index was $155.1 \%$, which was significantly reduced compared with controls $(p<0.005$; Table IV). For carriers with no EOG abnormalities, the Arden index was not significantly different from the controls.

Reduction of the scotopic b wave ERG amplitude occurred in 6 of the 10 patients. Delay, as well as reduction of the scotopic $b$ wave amplitude, occurred in 4 of the $10(40 \%)$ patients. Two further patients also had reduction of the amplitude and delay of the photopic and $30 \mathrm{~Hz}$ ERG. Another patient had reduction of the photopic ERG amplitude but normal $30 \mathrm{~Hz}$ ERG amplitude. Mean ERG values are seen in Table IV.

A summary of the electrophysiological and fundal abnormalities in groups 1, 2 and 3 is given in Table $\mathrm{V}$.

Results of Patients who Underwent ERG Investigation using 3 Log Units Below Standard Flash to 1 Log Unit Above Standard Flash Scotopic Stimuli

Ten patients examined over the past 18 months were investigated with the above stimuli. Of these 10 patients, 4 were obligate carriers (group 1), 2 were possible carriers (group 2), and 4 belonged to group 3 (Figs. 2, 3). Eight of the 10 heterozygotes had an abnormal scotopic b wave amplitude saturation curve. Figure 5 shows a significant reduction in $V / V_{\max }$ at 1 and $2 \log$ units below standard flash intensity amongst these 10 patients $(p<0.005)$. Six of these had a normal EOG, and in 2 the abnormal scotopic $b$ wave saturation curve was the only electrophysiological abnormality, apart from a delay of the intense flash scotopic $b$ wave. In 1 patient an abnormal rod saturation curve was the only abnormal finding, since the scotopic $b$ wave was of normal latency. The curve of scotopic b wave latency versus light intensity is seen in Figure 6 and 

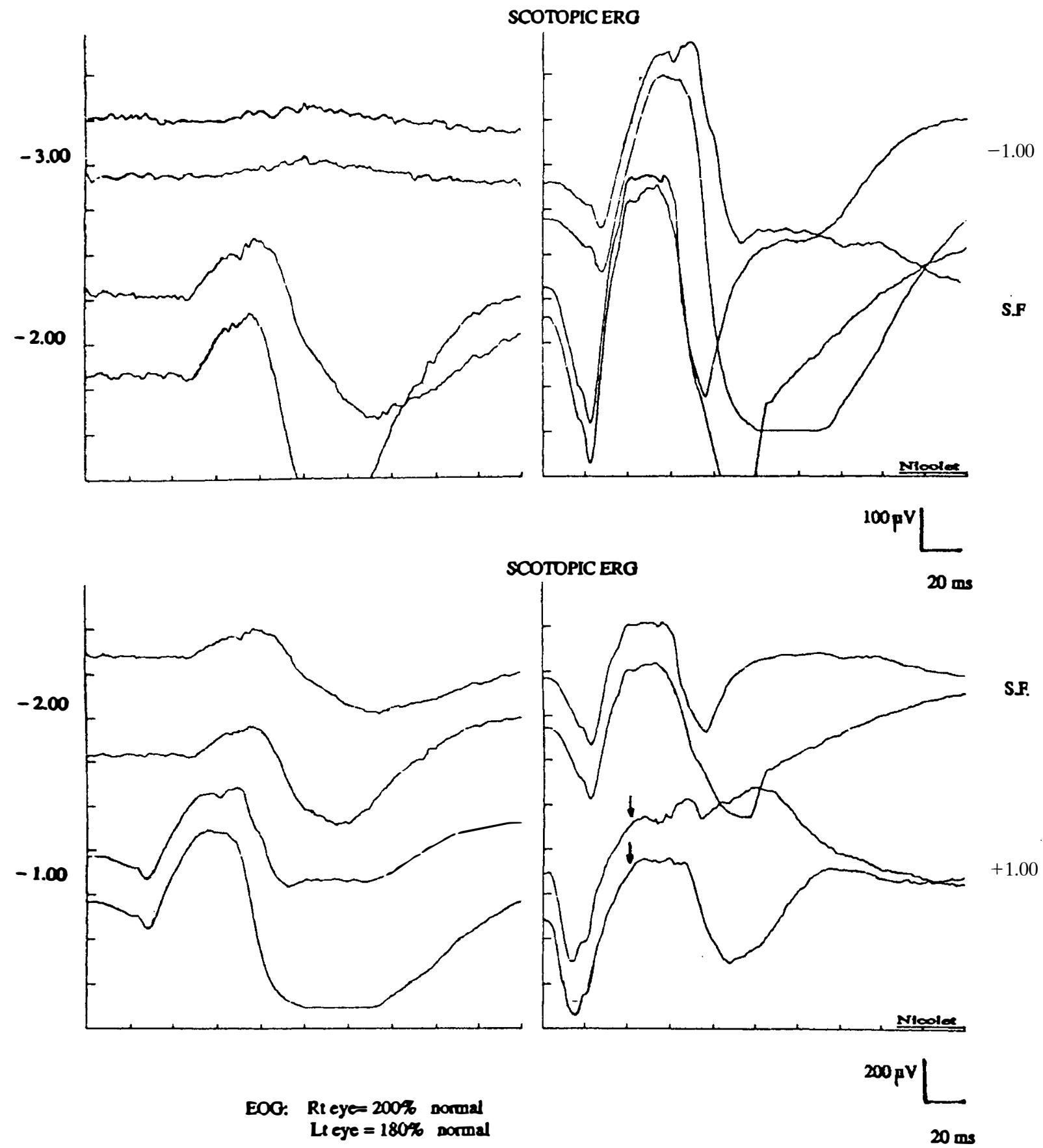

Fig. 2. DG, aged 25 years. Reduced ERG amplitude to 3 log units below standard flash and delay of intense flash ERG. This subject had normal EOG.

shows a significant increase in scotopic b wave latency at 1 log unit above standard flash intensity $(p<0.01)$.

\section{DISCUSSION}

This study confirms the value of ocular electrophysiology in the diagnosis of the heterozygous state of XL-RP. A classification of carriers into three distinct groups was used as the most appropriate method of evaluating the results. In particular, we have used obligate carriers to identify the incidence of electrophysiological and fundal abnormality amongst female carriers to XL-RP. Like Arden et al..$^{5}$, we found similar incidences of ERG abnormalities in obligate and non-obligate carriers.

A delay of the $30 \mathrm{~Hz}$ cone $\mathrm{b}$ wave has been reported as being a significant abnormality in carriers of XL-RP, ${ }^{2,4.5}$ whereas in this study only $45 \%$ of the obligate heterozygotes had a delay of the cone $b$ wave. Furthermore, our total incidence of ERG abnormality amongst obligate carriers is lower than in other studies using similar methodology. Arden et $a l .{ }^{5}$ reported a $57 \%$ incidence of prolonged $30 \mathrm{~Hz} \mathrm{~b}$ wave latency and a $50 \%$ incidence of reduction of 

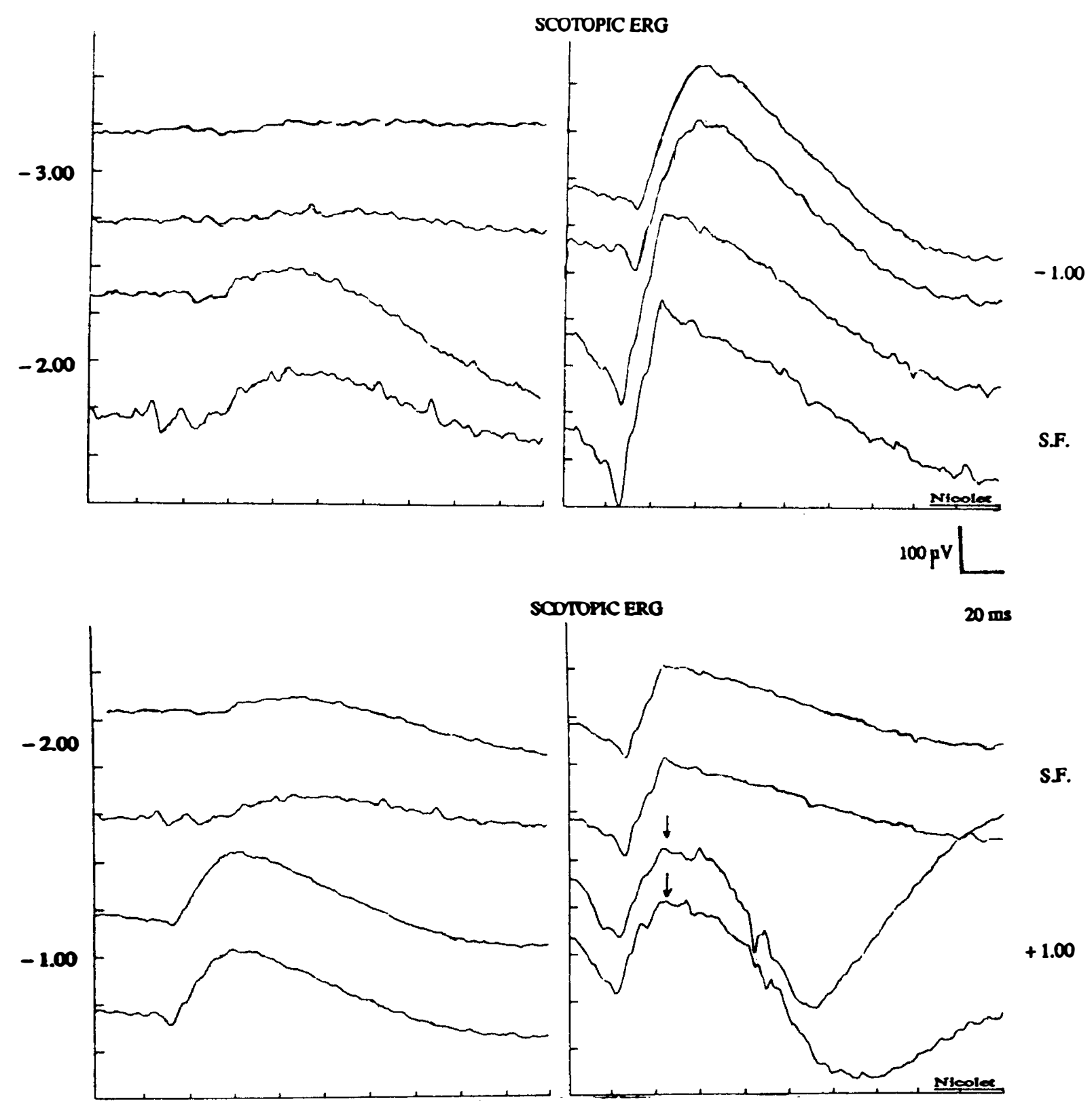

EOG: Ri eye $=145 \%$ roduced

Leye $=145 \%$ roduced

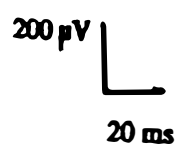

Fig. 3. $P B$, aged 48 years. Reduced ERG amplitude to 3 and 2 log units below standard flash but normal response to standard and intense flash. This subject also had reduced EOG in both eyes.

scotopic ERG amplitude. Berson et al. ${ }^{10}$ reported an $83 \%$ incidence of abnormal scotopic responses, while $75 \%$ of the patients had a delay of the $30 \mathrm{~Hz}$ b wave response. Fishman et al. ${ }^{6}$ reported a $74 \%$ reduction of the ERG scotopic b wave, an $81 \%$ photopic b wave reduction and an incidence of $51 \%$ for delay in the $30 \mathrm{~Hz}$ cone $\mathrm{b}$ wave. It is notable that Berson et al. ${ }^{10}$ found only 3 cases $(13 \%)$ where a delay of the cone $\mathrm{b}$ wave was the only ERG abnormality, which compares with the 2 carriers $(6 \%)$ in this study.

As in the studies by Arden et al. ${ }^{5}$ and Jacobson et al. ${ }^{4}$ we have in 10 patients constructed a curve of scotopic b wave amplitude versus stimulus intensity, in order to obtain a scotopic b wave saturation curve. We have also plotted intensity against latency and have measured intense flash scotopic $b$ wave latency in all patients. Neither Arden et al. ${ }^{5}$ nor Jacobson et $a l .{ }^{4}$ described any differences in scotopic b wave latency between carriers and controls. However, Arden et $_{\mathrm{al}}{ }^{5}$ did report a difference of approximately $6 \mathrm{~ms}$ in latency at saturation. This compares to our finding of $3.4 \mathrm{~ms}$ at saturation, which was significant 


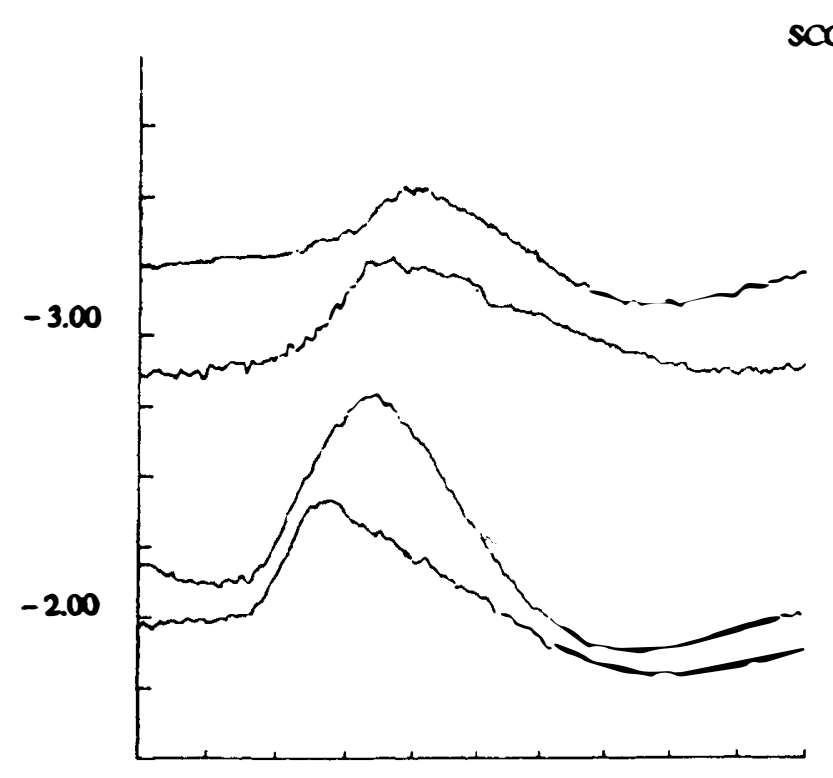

SCOTOPIC ERO

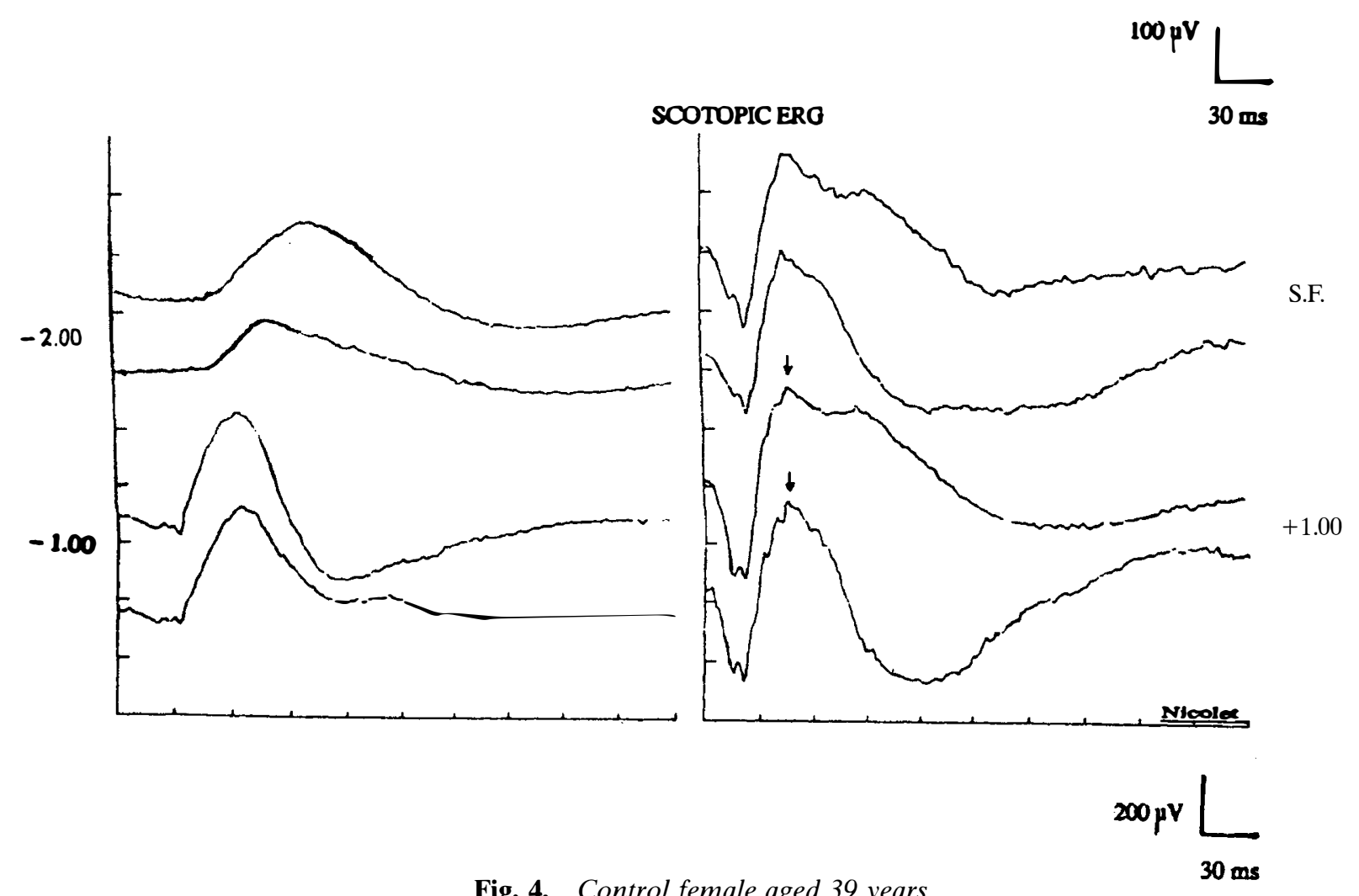

Fig. 4. Control female aged 39 years.

but did not occur at any other stimulus intensity. This suggests that plotting the saturation curve to obtain scotopic ERG b wave latency at saturation may increase the diagnostic sensitivity of the ERG.

To our knowledge, this is the first relatively large series of obligate carriers to undergo both ERG and EOG investigations. An earlier study by $\mathrm{Krill}^{3}$ reported abnormal EOG in 2 of 4 carriers, who also had abnormal ERG. Bird ${ }^{11}$ described EOG abnormalities in $60 \%$ of female relatives of XL-RP patients and ERG abnormalities in only $30 \%$. However, most of these females were not obligate carriers. A more recent study by Pinckers et al. ${ }^{13}$ of 32 carriers, described a $50 \%$ incidence of EOG abnormality. However, this study was not confined to obligate carriers and no ERG abnormalities were described. In our study, the incidence of EOG abnormality amongst obligate carriers was $41 \%$, but it is notable that EOG abnormalities in the absence of ERG abnormalities occurred in 2 obligate carriers. Furthermore, all carriers with abnormal EOG had an Arden index of less than $160 \%$, which is below the laboratory limit of $170 \%$. The EOG is a robust test. It is relatively simple to perform, compared with the 


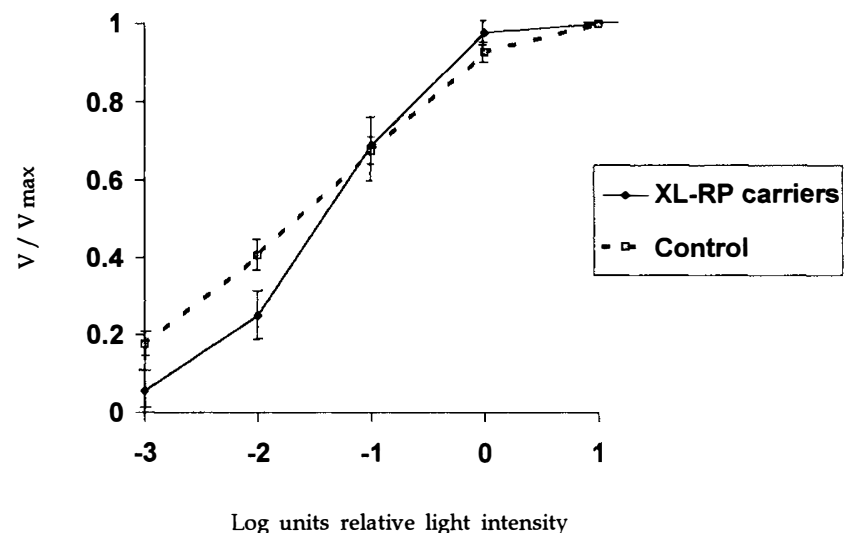

Fig. 5. Scotopic $b$ wave amplitude ratios $\left(\mathrm{V} / \mathrm{V}_{\max }\right)$ versus $\log$ units of light intensity $(0=$ standard flash). Significantly reduced ratios at 3 and $2 \log$ units below standard flash are seen in the XL-RP carrier group compared with the control group.

ERG, which requires strict standardisation. An abnormal EOG can be helpful in the evaluation of carriers with normal or equivocal fundi and equivocal ERG findings.

This study indicates that a major proportion of obligate carriers have a high percentage of reduction and delay of the scotopic ERG, suggesting marked rod malfunction. However, the variability of fundal and electrophysiological findings is in agreement with the Lyon hypothesis, ${ }^{14}$ which suggests that there might be patches of normal and abnormal retina in heterozygotes.

It is notable that the ERG even in combination with the EOG identified only $77 \%$ of the obligate carriers - the same proportion as detected by fundus examination alone. A combination of electrophysiology and fundus examination identified $93 \%$ of obligate carriers, leaving 2 carriers $(7 \%)$ who could be identified only by family history. The goal of identifying all carriers of XL-RP by these methods has therefore eluded us.

The incidence of EOG/ERG abnormality was significantly higher in obligate carriers over 40 years of age. Furthermore, scotopic ERG amplitude was significantly higher in the possible carrier group, which consisted of females younger than 40 years of age, and the mean EOG value was significantly lower in the group 3 carriers, which consisted of females over 20 years of age. These results suggest that age has a significant influence on both the incidence and the magnitude of EOG/ERG abnormality, which is in agreement with previous reports. $5,11,12$

This study also shows that there is a trend towards a higher incidence of fundal abnormality amongst older obligate carriers, but this does not reach significance. It therefore appears that the incidence of fundus abnormality is less age dependent than the incidence of electrophysiological abnormality. This means that careful fundus examination is of parti-

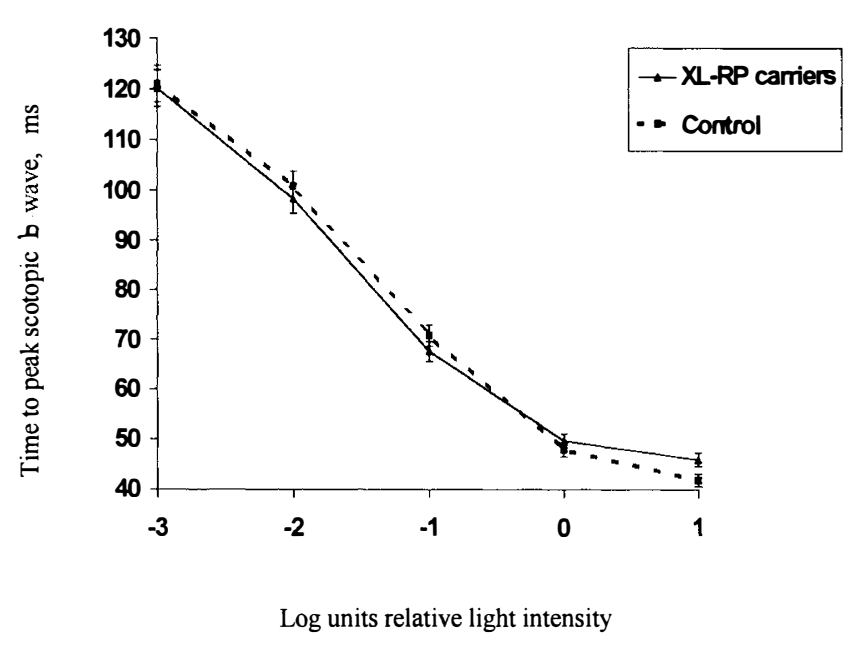

Fig. 6. Mean ( $\pm 1 S E$ ) scotopic b wave latency versus log units of light intensity $(0=$ standard flash $)$. Significantly increased latency at 1 log unit above standard flash is seen in the XL-RP carrier group compared with the control group.

cular importance in the identification of young carriers who may have normal electrophysiological findings.

The finding of a relatively large number of obligate carriers $(5 ; 16 \%)$ who had normal fundi but abnormal electrophysiological findings suggests that abnormal electrophysiological findings alone can be regarded as evidence of the carrier state of XL-RP. This means that the number of carriers amongst our group 2 and 3 females may have been underestimated.

In conclusion, the results of this study suggest that careful fundus examination together with EOG and ERG recordings, including dim flash scotopic stimuli and intense flash scotopic $b$ wave latency measurements, would be the combination of choice in the detection of carriers of XL-RP.

We wish to acknowledge the support of the British Retinitis Pigmentosa Society and Miss Elspeth Hewitt, Nurse at the Genetic Clinic at the Birmingham and Midland Eye Hospital.

Key words: Cone, Electro-oculogram, Electroretinogram, Female carriers, Fundus, Rod, X-linked retinitis pigmentosa.

\section{REFERENCES}

1. Fishman GA. Retinitis pigmentosa: genetic percentages. Arch Ophthalmol 1978;96:822-6.

2. Berson EL, Gouras P, Gunkel RD, Myrianthopoulos NC. Rod and cone responses in sex-linked retinitis pigmentosa. Arch Ophthalmol 1969;81:215-25.

3. Krill AE. Observations of carriers of X-chromosomallinked chorioretinal degenerations. Do these support the 'inactivation hypothesis'? Am J Ophthalmol 1967; 64:1029-40.

4. Jacobson SC, Yagasaki K, Feuer W, Román AJ. Interocular asymmetry of visual function in heterozygotes of X-linked retinitis pigmentosa. Exp Eye Res 1989;48:679-91. 
5. Arden GB, Carter RM, Hogg CR, Powell DJ, Ernst WJK, Clover GM, et al. A modified ERG technique and the results obtained in X-linked retinitis pigmentosa. Br J Ophthalmol 1983;67:419-30.

6. Fishman GA, Weinberg AB, McMahon TT. X-linked recessive retinitis pigmentosa: clinical characteristics of carriers. Arch Ophthalmol 1986;104:1329-35.

7. Gieser DK, Fishman GA, Cunha-Vaz J. X-linked recessive retinitis pigmentosa and vitreous fluorophotometry: a study of female heterozygotes. Arch Ophthalmol 1980;98:307-10.

8. Bird AC, Hyman V. Detection of heterozygotes in families with $\mathrm{X}$-linked pigmentary retinopathy by measurement of retinal rhodopsin concentration. Trans Ophthalmol Soc UK 1972;92:221-8.

9. Heck AF. Presumptive X-linked intermediate transmission of retinal degenerations: variations and coincidental occurrence with ataxia in a large family. Arch Ophthalmol 1963;70:143-9.

10. Berson EL, Rosen JB, Simonoff EA. Electroretinographic testing as an aid in detection of carriers of Xchromosome-linked retinitis pigmentosa. Am J Ophthalmol 1979;87:460-8.

11. Bird A. X-linked retinitis pigmentosa. Br J Ophthalmol 1975;59:177-99.

12. Bundey S. X-linked disorders. In: Wald NJ, editor. Antenatal and neonatal screening. Oxford: Oxford University Press, 1984:114-5.

13. Pinckers A, van Aarem A, Brink H. The electrooculogram in heterozygote carriers of Usher syndrome, retinitis pigmentosa, neuronal ceroid lipofuscinosis, Senior syndrome and choroideremia. Ophthalmic Genet 1994;15:25-30.

14. Lyon MP. Gene action in the X-chromosome of the mouse (Mus musculus). Nature 1961;190:372-3. 